\title{
РАЗМЫШЛЕНИЕ НАД КНИГОЙ «ЯВЛЯЕТСЯ ЛИ ЭГОИЗМ АМОРАЛЬНЫМ?»
}

\begin{abstract}
Аннотация. В статье представлен обзор последней книги немецкоязычных авторов в области этической мысли Хельги и Герберта Херцев (Helga E. Hӧrz, Herbert Hӧrz). Книга представляет собой попытку описания основных моментов и смысловых линий возможной «этики неомодерна», той теоретической системы, которая могла бы возродить ценности и оптимистические ожидания эпохи Просвещения, учитывая при этом критические замечания эпохи Постмодерна. Основным моментом при построении новой этики для авторов становится переосмысление того значения, которое имеют отношения эгоизма и альтруизма для нравственной философии. В книге рассматривается не метаэтические или сугубо прикладные вопросы. Отталкиваясь от насущных проблем, в которых «увяз» современный мир, Хельга и Герберт ищут основу, что смогла бы стать помощником в разрешении кризисных ситуаций и защитой от угрожающего, антигуманного развития цивилизации. Статья представляет собой обзор книги, помимо сжатого пересказа/интерпретации присутствует и ряд критических замечаний с попыткой осмысления книги как целого. Публикуется обзор немецкой книги, которая мало известна российскому читателю, ктому же книга на немецком языке и перевод ее на русский в ближайшее время не планируется. Книга вышла в 2013 году, посвящена актуальным современным проблемам с учетом и анализом многих последних достижений в этической мысли.
\end{abstract}

Ключевъе слова: этика, мораль, эгоизм, альтруизм, этика неомодерна, кризис, гуманность, прикладная этика, постмодерн, Просвещение.

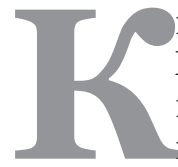

нига профессоров Хельги и Герберта Херцев «Является ли эгоизм аморальным? Основания этики неомодерна» ${ }^{1}$ вышла в 2013 г. и стала своеобразным итогом более чем полувековой деятельности каждого из авторов в области этических исследований. Хельга и Герберт - учёные, которым принадлежит огромное число научных исследований и публикаций по широкому спектру проблематики. Хельга Херц являлась видным участником феминистского движения в ГДР, представителем этой страны на конференциях ООН по правам женщин. Ее муж Герберт начинал свою научную деятельность в области физики, тесно работал и работает над проблемами прикладной этики в области науки и техники, занимал ряд высокихуниверситетских должностей.

Авторы получили высшее образование и большую часть жизни прожили в ГДР, именно через

\footnotetext{
${ }^{1}$ Hörz Helga E., Hörz Herbert. Ist Egoismus unmoralisch? Grundzüge einer neomodernen Ethik. Berlin: trafo Verlagsgruppe Dr. Wolfgang Weist, 2013. 460 s. В дальнейшем ссылки на эту книгу в тексте с указанием на страницы.
}

перспективу накопленного в этой части Германии опыта и рассматриваются многие проблемы, которые обсуждаются в книге. «Реальный социализм», советское государство и марксизм для них не что-то архаичное и исключительно оставшееся позади, а длящаяся, требующая переосмысления реальность. Подчеркивая большое количество, по их мнению, прогрессивных и положительных моментов, авторы далеки и от идеализации системы Восточной Германии, видят в ней темные, жесткие, склонные к авторитарности и косности черты. Они отмечают, что резкая и бескомпромиссная критика ГДР является такой же односторонней, как и «ностальгически отделанный, хвалебный гимн жизни полной свершений и счастья» (S. 121). В книге раскрывается та сторона реальности, которая не так часто встречается в современной научной литературе. При попытке не игнорировать недостатки, делается акцент на достижениях системы в ГДР, авторами подчеркивается, что по некоторым направлениях, в том числе тем, которые касаются фундаментальных прав человека, Восточная Германия превосходила ФРГ. 
Несмотря на свое название, книга не ограничивается рассмотрением этической проблематики эгоизма. Речь идет о попытке обоснование основных черт «этики неомодерна», а начиная с седьмой главы, предпринимается критическое рассмотрение широкого спектра практических, прикладных дилемм и проблем сквозь призму возводимой конструкции. По мнению авторов, отправные точки, которые могли бы сформулировать «этику неомодерна", следует искать в концептуальных основах модерна и идеях Просвещения, но рассмотренных через и с учетом критики постмодерна. Цель Хельги и Герберта дать контуры этики, как возможной науки и мировоззрения (vgl. S. 46). Проблематика эгоизма и альтруизма, как двух полярных точек моральной ориентации, становится важной основой для построения «этики неомодерна», но не является единственной темой книги.

Авторы представили свою книгу как небольшой компендиум. Постулируемое вначале кризисное положение человечества, вовлеченное в многочисленные конфликты и кризисы, требует поиска новых ценностных и этических основ, которые смогли бы быть применимы для разных областей. Отсюда широкий размах тем: от проблем пренатальной медицины до трактовки связи теории и практики у Маркса в современной мысли, от уровня доверия в государстве до прав женщин, от критики современного ему мира Клагесом до рассмотрения мирового этоса Кюнга, от проблемы взаимосвязи души и тела до плюсов и минусов образовательной системы ГДР в сравнении с ФРГ, от отношений между религией и наукой до кризиса демократии.

Проблематика эгоизма и альтруизма по мере изложения то выдвигается на первый план, то несколько затушевывается обилием предлагаемых тезисов, которые могли бы помочь решению конкретных, но при этом очень часто общечеловеческих проблем. Книга содержит и небольшой исторический очерк, где приводятся идеи ряда философов. Особенно подробно авторы останавливаются на марксизме, что неудивительно, так как сами авторы причисляют себя к марксистам (vgl. S. 107). В то же время они постулируют выход за рамки примитивного редукционизма своих этических рефлексий к интересам и/или сознанию класса.

Книга содержит четырнадцать глав. Первая из них обрисовывает вызовы этической мысли со стороны разнообразных проблем и кризисных явлений современности, которые проявились с небывалой до этого остротой. Вторая кратко затра- гивает сущность эгоизма, определяя эгоизм, как «максиму продолжения жизни» (vgl. S. 17). Третья глава уточняет возможности и суть этики, в том числе и взаимосвязь этики и морали. В четвертой главе обосновывает необходимость построения «этики неомодерна», которая смогла бы стать адекватным ответом на актуальные проблемы. Пятая глава разбирает на примерах из истории философской, художественной, политической и религиозной мысли, этическое противостояние и отношение между эгоизмом и альтруизмом. Шестая глава выводит основные черты и основания «этики неомодерна». Седьмая глава касается вопроса прогресса технологий, вопросов повышающихся рисков экологических катастроф, соотношение требований к развитию науки и техники, с одной стороны, и гуманизма, с другой. В восьмой главе затрагиваются проблемы биологии и в первую очередь биоэтики. В девятой главе авторы останавливаются на образах возможного будущего, его ценностных и нормативных основах. Десятая глава посвящена проблемам и критике современной формы западной демократии, в частности тем необходимым усовершенствованиям, реформам, которые требуются для возврата демократий к их гуманным истокам. Одиннадцатая глава касается вопросов прав женщин, особое внимание авторов вызывают практические проблемы. Хельга Херц делится своим опытом участия в международных конференциях, опытом работы над международными нормативными документами, сравнивает законодательства ФРГ и ГДР. В главе подчеркивается, что в ряде вопросов ГДР создавала лучшие предпосылки для гендерного равенства. В двенадцатой главе ставится вопрос о соотношение между наукой и религией, знанием и верой. Тринадцатая глава описывает проблему «дефицита утопии» (das Utopie-Defizit), авторы касаются утопических образов, которые присутствовали в философии, науке и политике, подчеркивают необходимость и важное значение «утопий» в нормативных и ценностных ориентациях человека. Наконец, четырнадцатая, заключительная глава задается вопросом обуместности, «своевременности» (zeitgemäß) этического и общечеловеческого оптимизма в двадцать первом веке. Авторы подчеркивают всю сложность и малореалистичность оптимистического развития в современном мире, но считают, что крайне неверным и «несвоевременным» были бы чувства отчаяния, трагизма и пессимизма.

Таким образом, в книге обсуждаются широчайший спектр вопросов и проблем, как будто задачей 


\section{Философия и культура 1(73) • 2014}

было подвести некий итог тех дискуссий, которые когда-либо волновали авторов. Не случайно, что Хельга и Герберт местами делятся личным опытом, приводят истории из своей жизни. Особенно важно, что почти каждый более-менее крупный раздел при обсуждении вопросов прикладной этики завершается своеобразным суммированием основных положений. Это показывает, что за каждым рассуждением стоит выработанная в течение годов практическая и теоретическая программа. Ниже в первую очередь будут затронуты теоретические основы книги и центральная тема отношения эгоизма и альтруизма. Многочисленные практические приложения и отступления останутся в основном за рамками обзора, хотя они сами по себе также представляют интерес.

Этика и мораль. Надо особо подчеркнуть, что в своей работе авторы иллюстрируют, проецируют и даже исходят прежде всего из реальных мировых процессов, практических проблем, в приложении к которым они и вырабатывают свой подход к этике. Сугубо теоретическая часть представлена слабо, по направленности книга представляет скорее попытку выработки основных характеристик общего этического подхода, который мог бы работать в каждом конкретном случае. Наиболее близки авторы к прикладной этике, точнее к попытке осмысления общих принципов прикладной этики, которые были бы способны работать в каждом из подразделов. Хелена и Герберт касаются почти всех основных разделов прикладной этики таких направлений, как экологическая этика, биоэтика, этика науки и техники, хотя этому и не посвящены специальные разделы, но в книге присутствует ряд замечаний по экономической этике, это же касается и информационной этики.

Этика понимается как «теоретическое прояснение (Erklärung) практических моральных поступков. Она предполагает общее обоснование критериев, которыми может быть измерено моральное и аморальное» (S. 24). Что касается источников, то это то, что «имеет основания в нашем социальном опыте» (S. 13), то есть в отношениях между индивидами, поведение которых детерминируется, с одной стороны, эгоизмом, а с другой, альтруизмом. Авторы категоричны в том, что касается предмета этики. Нормы изменяются, а этика не может являться «универсальным и осуществимым руководством к нравственным поступкам всех людей» (S. 24), при этом немецкие исследователи утверждают, что для поведения людей свойственна тенденция к более «адекватному человече- скому» обращению друг с другом и есть надежда на осуществление идей гуманизма, которые были заложены рядом мыслителей. На основе этих двух положений и предлагается создание «этики неомодерна». Этика и мораль имеют «различные детерминанты», то есть их нельзя свести к чему-то заложенному природой, этика и мораль не являются безусловно универсальными, а моральные императивы и решения «не могут быть объяснены единственно из теоретической рефлексии» (S. 13). Отсюда понятно и утверждение, что этика не решает, а проясняет моральные проблемы. В подходах к этике различается: универсализм, плюрализм и эволюционизм.

Мораль, для авторов, выступает как содержание и предмет теоретических экспликаций этики. Авторы почти исключительно останавливаются на социальном измерении морали, они так и утверждают, что «мораль охватывает отношения людей друг к другу» (S. 34). Каждое общество имеет свое собственное понимание того, что способствует его выживанию, выработки ее идентичности и улучшению условий, отсюда развитие специфических для каждого общества (авторы часто используют слово «общность» (Gemeinschaft)) социальных ценностей. Получается, что «функция морали» заключается в том, чтобы «сохранять (поддерживать) соответствующую социальную систему» (S. 35).

Под аморальным понимается преобладание и подавление либо эгоизма, либо альтруизма. Одна крайность уводит в тоталитарный террор, другая в неолиберализм, эксплуатацию, экономические кризисы и общество потребления.

Для понимания морального авторы выводят следующую формулу, которая, безусловно, имеет известные основания в идеях прошлого и очень созвучна им: «Моральное, или по-другому выражаясь морально хорошее, есть то, что собственный интерес позволяет осуществлять таким образом, чтобы не вредить и не препятствовать другим людям» (S. 21). В тоже время: «Любая форма эксплуатации, подавления и диффамации - аморальна» (ibid).

Разница между этикой и моралью в том, что в то время как мораль поддерживает и соответствует определенной общности людей, то этика является научной экспликацией и объяснительным инструментом для морального поведения и поступков. Фактически, в этом разделении для авторов звучит известное деление $Ф$. Тёнесса на общность (Gemeinschaft) и общество (Gesellschaft). Отсюда двое немецкий ученых заключают, что конкретный поступок может как соответствовать развиваемой 
в определенной общности этики, но также может и не сводится, а порой даже противоречить ей. По их мнению, моральное поведение не ориентируется на различные этики.

Авторы выступают против одномерного и упрощененного редукционизма как морали, так и этики к антропологии, к эволюционным теориям или, проще говоря, выступают против натурализма в мысли о морали. Последнее направление представлено в первую очередь ученым Хансом Мором (Mohr) и его книгой «Эволюционная теория познания, этика и мораль» (Evolutionäre Erkenntnistheorie, Ethik und Moral), другим представителем выступает Ричард Докинз с его известным «Эгоистичным геном» и «меметикой». Отдавая должное научной эрудиции и важности биологических, антропологических, эволюционных исследований, Хельга и Герберт призывают учитывать несколько составляющих в образовании морали: биологические, психические и социальные, каждое из которых не может быть без многочисленных искажений сведена к другой.

Эгоизм и альтруизм. В книге выделяются разные аспекты отношения между эгоизмом и альтруизмом, они простираются от описания этой проблематики на уровне исследований в области биологии, медицины, нейрохирургии до небольшой каталогизации учений этики по критерию близости их ориентации на эгоизм или альтруизм. По критерию преобладания ориентации на эгоизм или альтруизм проводится сопоставление гедонизма и стоицизма, Аристотеля и Платона, Лао-цзы и Конфуция. Тоже самое в виде зарисовки относится к сопоставлению разных религий, а также в отношении стилей жизни бюргера и гражданина. Авторы описывают возможный общий мировоззренческий взгляд на действительность как арену взаимодействия между эгоизмом и альтруизмом. Авторы пишут: «Действительность является измерителем силы между более эгоистическими и более альтруистическими людьми. Конкретные общественные отношения сдвигают центр тяжести то на одну, то на другую сторону» (S. 45).

Полученный взгляд используется в книге в первую очередь для оценки общественного строя и экономической системы. Тогда как капиталистическая «хищническая мораль» (по-немецки «мораль акулы» (Haifischmoral)) делает сильный крен в сторону эгоизма, то цель гуманного общества добиться солидарности, но, что важно, без того, чтобы устранить эгоизм. Надо отметить, приоритет для авторов остается все-таки на сто- роне альтруизма, так как эгоизм допускается настолько, насколько «он может быть канализирован в интересах общности» (ibid). Социализм в данном представлении выступает как то, что «смягчает этику конфронтации» (S. 6о), которую проводит капитализм. Таким образом, симпатии авторов оказываются на стороне социализма, а лейтмотивом книги, который неоднократно звучит с ее страниц, становятся слова Маркса из «Манифеста коммунистической партии»: «Свободное развитие каждого является условием свободного развития всех» (die freie Entwicklung eines jeden die Bedingung für die freie Entwicklung aller ist).

Авторы не устают подчеркивать исторические примеры того, как в заостренной форме эгоизм вырождается в «эгоцентризм», а альтруизм в террор и насилие над индивидами. Хотя, опять же, первая сторона представлена несравнимо более выпукло и подробно. Изначально альтруизм уже выступает в привилегированном, с этической точки зрения, положении. Но при всей «предвзятости» авторов, книга не содержит в себе хвалебных, односторонних песен самопожертвованию и жизни исключительно ради будущих поколений. Для Герберта и Хелены Херцев, построение новой этики должно основываться на ценностях свободы, справедливости и братства, на гармоничных и социально отрегулированных отношениях между эгоизмом и альтруизмом. Таким образом, на главный вопрос книги: «является ли эгоизм аморальным?» авторы дают однозначный ответ - нет. В тоже время они не ставят вопрос: аморален ли альтруизм? Это предопределяет определенный «этический крен» в построениях. Можно сказать с высокой степенью достоверности, что это обусловлено позицией авторов, которые постулируют преимущественно эгоистический характер западной капиталистической цивилизации, пафос марксизма и социализма регулярно проступает между строк, но он не носит догматического или пропагандистского характера.

Построение «этики неомодерна». Современное общество находится в центре столкновения огромного числа кризисных явлений. Именно через остроту кризисов, через появление новых конфликтов и обосновывают авторы необходимость, насущную потребность в «этике неомодерна». Наиболее серьезные вызовы являются результатом глобальных изменений, произошедших, с одной стороны, в связи с развитием Западной цивилизации, а с другой, с крушением альтернативы в виде Советского Союза (vgl. S. 52). Сама глобальность мира становится источником проблем 


\section{Философия и культура 1(73) • 2014}

и конфликтов, требующих осмысления с этических позиций. Авторы отмечают военные и групповые конфликты (vgl. S. 54), цивилизационные кризисы, вызванные восприятием человека себя как формулирующим свои интересы без оглядки на окружающую среду и на возможные отрицательные последствия применяемых технологий (vgl. S. 56), кризис управления (Herrschaftskrise), который связан как с цивилизационным кризисом, так и с общей антигуманным использованием власти. В области самоосмысления и самоидентификации авторы диагностируют кризис смысла (Sinnkrise) и теоретический кризис (Theoriekrise). Отчасти авторы повторяют известное со времен Оствальда Шпенглера, Альфреда Вебера и ряда других мыслителей, противостояние между цивилизацией и культурой (vgl. S. 56-57).

Хельга и Герберт особо останавливаются на анализе кризиса смысла, для них это принципиальный вопрос, так как, согласно их взглядам, человек теряет свое центральное значение в конкурентной среде Западного общества. При этом признаются прорывы, которые были осуществлены в области прав человека, свободы совести, свободы вероисповедания, но, по мнению авторов, это результат развития и заслуга не только Западного капиталистического мира. Вопрос кризиса смысла для них тесно связан с господствующей картиной человека (vgl. S. 62), которая порождена и тем, что человек потерял свое твердое место, так как он больше не определяется однозначно через божественное начало. Человек сближается с животным, теряется его специфика как уникального нравственного субъекта. «Этику неомодерна» они предлагают строить на основе гуманизма, так как она и является частью гуманизма (vgl. 188), который в свою очередь понимается как: «Служба гуманистическим традициям, как программа к освобождению человечества от нужды, подавления и эксплуатации» (S. 188).
Авторы причисляют «этику неомодерна» к «реальной этике», противопоставляя ее к до этого развивающейся «этики идеальной» (Idealethik), последняя в отличие от первой апеллировала к «абстрактным индивидам». Для «реальной этики неомодерна» выводится несколько существенных характеристик, которые принципиально отличают ее от неактуальной более «идеальной этики», они следующие:

1. Требования к индивидам рассматриваются через то общество, в котором они живут;

2. Моральный ответ индивидов рассматривается также через социальные классы, так как это является существенным для нравственного поведения;

3. Люди рассматриваются как «биопсихосоциальные» единства, то есть не допускается сведение нравственного исключительно одному аспекту реальности;

4. Культурное различие должно рассматриваться через ценностный канон социальных идентичностей (vgl. S. 191).

Этими характеристиками не исчерпывается попытка описания новой «этики неомодерна», авторы предпринимают исследование основ социальных и природных гипотез происхождения морали, кризисов идентичностей, влияния этических систем на развитие общества. Выводится ряд гуманистических критериев и обязательств, которые должны помочь выделению новой этики. Используется широкий спектр идей, куда включаются и идеи эпохи Просвещения, немецкой и мировой философии, а также марксистские ценности и права человека. Ключевые места в «этике неомодерна», согласно Хельге и Герберту, должны занимать: внимание к достоинству человека, уважение к личности, повышение качества жизни на всей планете, снижение экологических и технологических рисков, интеграция инвалидов и людей с ограниченными возможностями.

\section{Список литературъ:}

1. Hörz Helga E., Hörz Herbert. Ist Egoismus unmoralisch? Grundzüge einer neomodernen Ethik. Berlin: trafo Verlagsgruppe Dr. Wolfgang Weist, 2013. $460 \mathrm{~s}$. 